\title{
Conduction System Pacing: Basis and Scope
}

\section{DR Vivek Kumar*, DR Vanita Arora}

Indraprastha Apollo Hospitals, New Delhi, India

*Corresponding Author: DR Vivek Kumar, Indraprastha Apollo Hospitals, New Delhi, India.

Received date: November 19, 2021; Accepted date: December 08, 2021; Published date: January 04,2022

Citation: V Kumar, V Arora. (2022). Conduction system pacing: basis and scope. Cardiology Research and Reports. 4(1); DOI: 10.31579/26929759/030

Copyright: (C) 2022 Vivek Kumar, This is an open-access article distributed under the terms of the Creative Commons Attribution License, which permits unrestricted use, distribution, and reproduction in any medium, provided the original author and source are credited.
Abstract ventricular desynchronization. LVEF) of $40 \%$ or less resulting in increased death or HFH.
Keywords: right ventricular pacing; heart failure; heart failure hospitalization

Long-term right ventricular pacing (RVP) is associated with more cardiovascular death, atrial fibrillation (AF), thromboembolic complications and heart failure(HF). RVP often results in prolonged QRS duration(QRSd) and

The ventricular desynchronization as a result of RVP leads to an increased risk of heart failure

hospitalization (HFH) and AF, and this effect is dependent on cumulative percent ventricular paced ( \% VP). In the sub-study from the MOST trial, it was evident that \% VP $>40 \%$ was associated with a 2.6-fold increased risk of HFH compared with pacing $<40 \%$ of the time despite preserved atrioventricular synchrony. Moreover this adverse effect of RVP induced ventricular desynchrony was more pronounced in patients with left ventricular ejection fraction(

\section{Abbreviations}

$\mathrm{AF}=$ Atrial fibrillation

$\mathrm{AV}=$ atrioventricular

$\mathrm{BBB}=$ Bundle branch block

$\mathrm{BVP}=\mathrm{Bi}$-ventricular pacing

$\mathrm{CRT}=$ Cardiac resynchronization therapy

$\mathrm{CSP}=$ Conduction system pacing

$\mathrm{HBP}=$ His bundle pacing

$\mathrm{HF}=$ Heart failure

$\mathrm{HFH}=$ heart failure hospitalisation

$\mathrm{HFrEF}=$ Heart failure with reduced ejection fraction

HOT-CRT $=$ His - Optimised CRT

HPS $=$ His Purkinje system

HPCD = His-Purkinje conduction disease

$\mathrm{HV}=\mathrm{His}$ to ventricular electrogram interval
LBBB = left bundle branch block

LBBAP $=$ Left bundle branch area pacing

LOT-CRT $=$ LBBP optimised CRT

$\mathrm{LV}=$ left ventricle/ventricular

$\mathrm{LVEF}=\mathrm{Left}$ ventricular ejection fraction

LVSP = Left ventricular septal pacing

NS-HBP $=$ Non selective HBP

PGR = Pulse generator replacement

$\% \mathrm{VP}=$ Percent ventricular paced

$\mathrm{QRSd}=\mathrm{QRS}$ duration

$\mathrm{RBBB}=$ right bundle branch block

$\mathrm{RV}=$ Right ventricle

RVP $=$ Right ventricular/ventricle pacing

$\mathrm{SND}=\mathrm{SA}$ nodal disease

$\mathrm{S}-\mathrm{HBP}=$ Selective HBP 


\section{Introduction}

Long-term right ventricular pacing (RVP) is associated with more cardiovascular death, atrial fibrillation (AF), thromboembolic complications and heart failure(HF) [1]. RVP often results in prolonged QRS duration(QRSd) and ventricular desynchronization.

The ventricular desynchronization as a result of RVP leads to an increased risk of heart failure

hospitalization (HFH) and AF, and this effect is dependent on cumulative percent ventricular paced ( $\% \mathrm{VP}$ ). In the sub-study from the MOST trial, it was evident that $\% \mathrm{VP}>40 \%$ was associated with a 2.6 -fold increased risk of HFH compared with pacing $<40 \%$ of the time despite preserved atrioventricular synchrony [2]. Moreover this adverse effect of RVP induced ventricular desynchrony was more pronounced in patients with left ventricular ejection fraction( LVEF) of $40 \%$ or less resulting in increased death or HFH [3].

Alternate RV sites, like mid septal or right ventricular outflow tract (RVOT) septal pacing have so far shown conflicting data in terms of QRSd narrowing as well as hemodynamic and clinical outcomes [4]. Strategies to reduce the percentage of RV pacing include algorithms that promote $\mathrm{AAI}(\mathrm{R})$ mode permitting first degree or Mobitz Type 1 heart block to occur. But it may not be effective in reducing \%VP in patients for whom VP is inevitable (e.g.complete heart block, AF with bradycardia). Even programming a long fixed AV delay above baseline PR interval though promotes intrinsic AV conduction to occur, but still results in $\% \mathrm{VP}>50 \%$ to occur in $88 \%$ of patients due to $\mathrm{PR}$ prolongation on exercise [5].

These considerations have led to the recommendation of cardiac resynchronization therapy (CRT) in patients needing pacemaker if there is left ventricular (LV) dysfunction. ${ }^{6}$ But the patients with normal LV function and indication for pacing are predominantly offered conventional pacing strategy with RVP. Of late conduction system pacing (CSP) has come up as a promising pacing strategy gaining acceptance worldwide. CSP involves implanting pacing lead targeting at various levels in the conduction system that includes His bundle and left bundle branch area. The idea is to circumvent AV block and achieve synchronized biventricular activation.

\section{Anatomy of Conduction system}

The compact AV node lies in the superficial paraseptal endocardium of the inferior right atrium. It is located along the septal portion of the tricuspid valve annulus towards the apex of the triangle of Koch. The His bundle arises as an anterosuperior extension from the compact AV node and passes into the central fibrous body of the septum. As It emerges out of the central fibrous body, it lies along the posterior and inferior margins of the membranous interventricular septum. Anatomical variations are common as the penetrating part of His bundle courses, commonly it is on the right-side of the membranous septum, but can be on the left side or course under the membranous septum just below the endocardium. ${ }^{7}$ After a short course $(5-10 \mathrm{~mm})$, the His bundle bifurcates into the right bundle (RBB) and the left bundle (LBB) at the crest of the muscular septum. The $\mathrm{RBB}$ is thin and compact, and courses down the right side of the interventricular septum anteriorly. RBB does not divide throughout most of its course until it approaches the base of the right anterior papillary muscle at the distal septal surface.

The left branch traverses the membranous septum and appears between the non-coronary and right coronary aortic cusps. The Left bundle is compact in the proximal 1 to $2 \mathrm{~cm}$ and it courses down in the subendocardium of the septal surface of the left ventricle. It then fans into an anterior (superior) fascicle (LAF) and a posterior (inferior) fascicle (PAF). The LAF courses towards the anterior-superior papillary muscle, and the LPF toward the posterior-inferior papillary muscle. Variably the proximal LBB also gives rise to Purkinje fibers to the septum, called the Septal fascicle. ${ }^{8}$ As the tricuspid valve is more apical than the mitral valve and septal leaflet of the tricuspid valve is attached to the membranous septum. The proximal part of the His bundle rests on the right atrial-LV portion of the membranous septum, and the distal His lies along the RVLV portion of the membranous septum . (Figure 1)

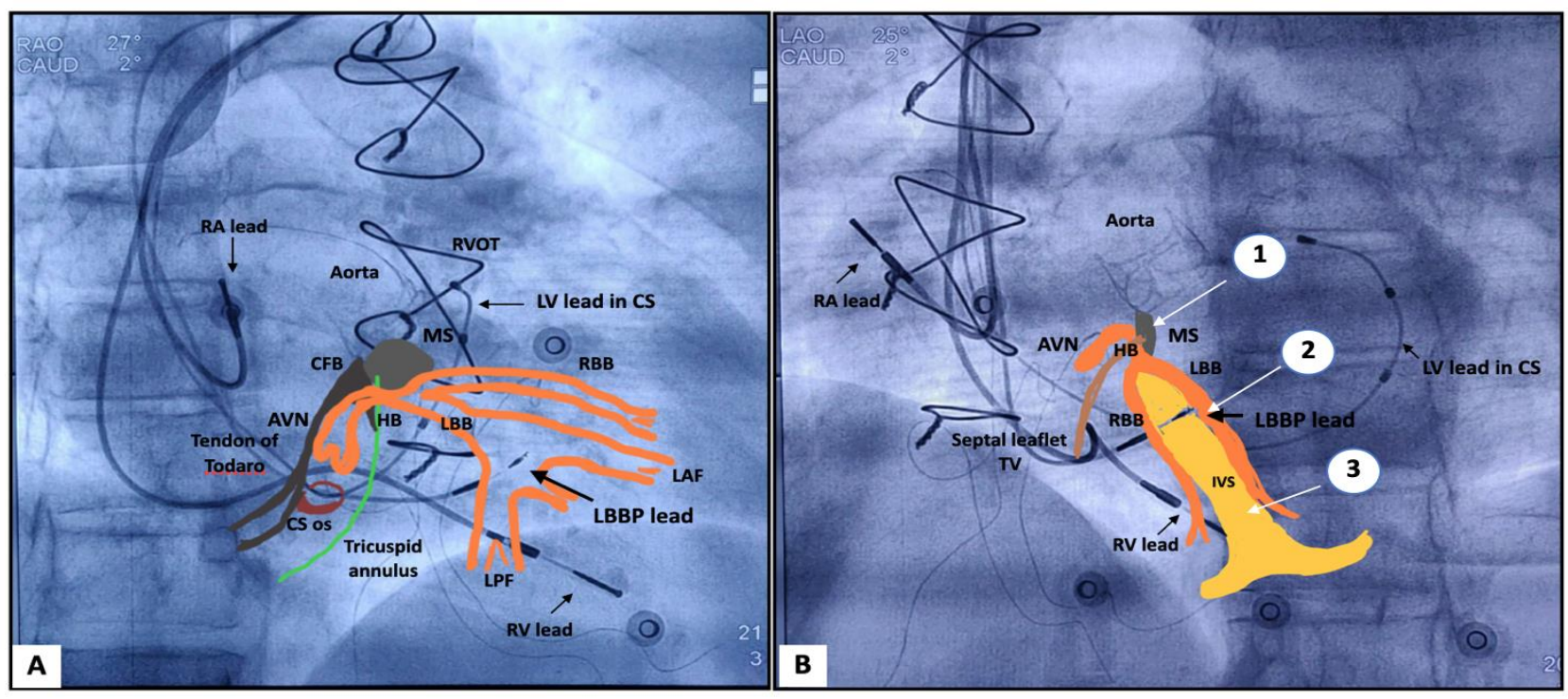

Figure 1. Diagrammatic illustration of conduction system anatomy for CSP in a patient with previous bio-prosthetic AVR, severe LV dysfunction and

$B V P-C R T$ non responder because of dislodged LV lead. Underwent successful LBBAP. AVN-Atrio Ventricular node, HB- His bundle, LBB- left bundle branch, RBB-Right bundle branch, LAF-Left anterior fascicle, LPF-Left posterior fascicle, CS os-Coronary sinus Ostia, LBBP-Left bundle branch pacing. 


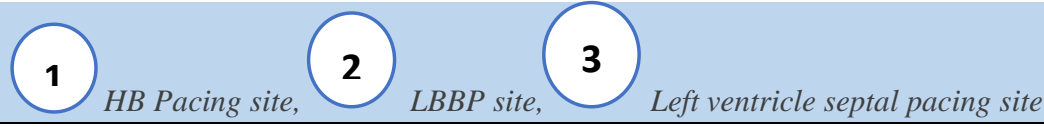

\section{Electrophysiological basis}

The targets for conduction system pacing are the His bundle (Both the atrial and ventricular portions of the His bundle) and the Left bundle branch area. In SA nodal disease (SND) where the AV node -His bundle Purkinje system is relatively disease-free, it is obvious that if His bundle is paced it will result in QRS morphologically identical to the baseline QRS. Interestingly in early experiments, it was shown that His bundle pacing (HBP) can even result in correction of bundle branch block(BBB) [9]. This was considered as a proof of concept for the proposed hypothesis of Longitudinal dissociation in the His bundle. It was Kaufmann and Rothberger who first postulated the idea of functional longitudinal dissociation in 1919 [10] The theory proposes that fibers destined for respective bundle branches are prefixed and bundled in the proximal His bundle. In the majority of cases, the bundle block manifestation is not a result of conduction delay in the anatomical bundle distally but as a result of conduction delay in proximal fibers. So pacing distal to the block result in normalization and narrowing of QRS morphology [11]. The anatomical basis to this hypothesis was given by James and Sherf in 1971 [12]. They observed that cells in His bundle were mainly arranged longitudinally and separated by fine collagen with minimal cross-connection. They gave an impression of parallel insulated channels for conduction and the bulk of cells were destined for the left bundle.

Interestingly it is observed that even in presence of evident distal block (LBBB with left axis deviation) [13].HBP can result in correction of block indicating additional mechanisms at play. It has been observed that there is some degree of output dependence during distal HBP. High output stimulus in the His area corresponds with a larger area of capture, thereby reaching beyond the block. ${ }^{14}$ It can recruit normal conducting fibers adjacent to abnormal myocardium causing the functional block. This will give an impression of non-selective HBP and the result would be normalization of BBB. (Figure 2) An alternate theory is based on the concept of "virtual electrode polarization", initially demonstrated in the mechanism of defibrillation [15]. The delivery of stimulus results in ion changes locally. If the stimulus is of sufficient strength it can create an electric dipole (with an anode and cathode), which can redistribute charges and increase the reach of the implanted pacing lead. Thereby recruiting fibers distal to the block and result in successful HBP. Because of anatomical and electrophysiological factors, it is not surprising that the average HBP threshold is higher than conventional pacing sites [16]. A His bundle capture threshold of $<2.0 \mathrm{~V}$ at $1 \mathrm{~ms}$ is acceptable, a higher threshold can be accepted provided the RV capture threshold is significantly lower [17].

In HBP, short AV delay needs to be set equivalent to native $\mathrm{AH}$ interval. Depending upon the lead position and His bundle anatomy ( intramyocardial, naked, or covered with fibrous tissue) [18]. HBP may be selective ( S-HBP) or nonselective (NS-HBP). In S- HBP the ventricular activation happens solely through the His Purkinje system (HPS), so the stimulus to ventricular activation (SV) interval is either equal to the native $\mathrm{HV}$ interval or even shorter than HV as in the case of BBB or proximal HV block. The QRS morphology is the same as the native QRS morphology but in the case of $\mathrm{BBB}$, it may result in correction of the block with a narrower QRS duration. NS-HBP results in additional activation of the septal myocardium. On electrogram, it is manifested as a pseudo-delta wave just after stimulus so the QRS duration will usually be longer than the native QRS. It may still result in correction of BBB and narrower QRS in HPCD. ${ }^{17} \mathrm{~S}$-HBP intuitively looks preferable over NSHBP, but the published data indicate that the clinical and hemodynamic outcomes are comparable [19].

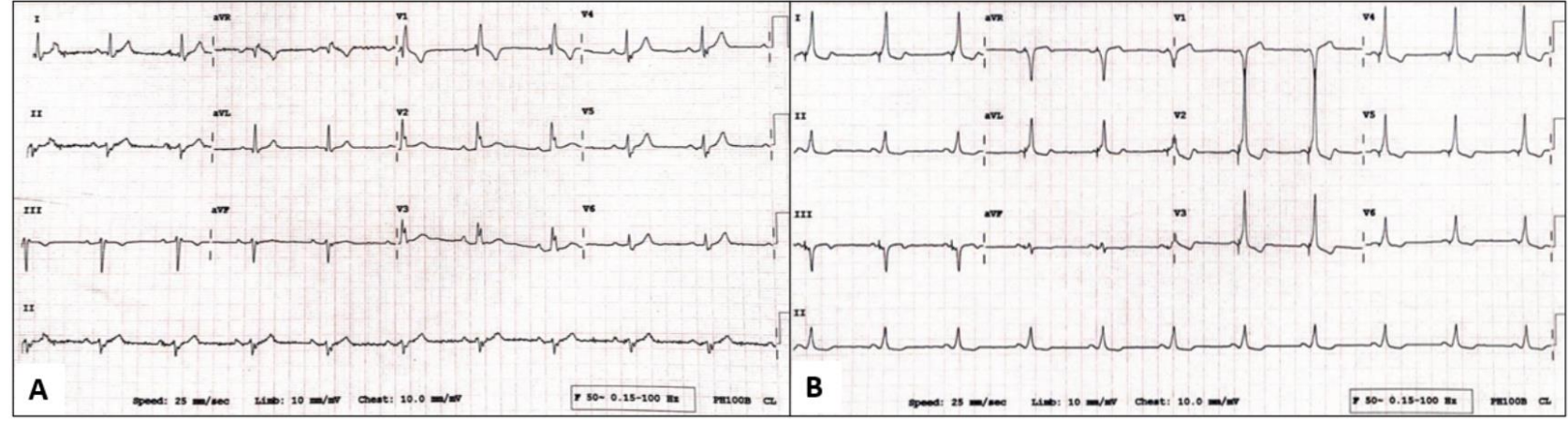

Figure 2. $H B P$ in Intermittent $C H B$. A. Trifascicular block with RBBB, LAHB and prolonged PR. B. NS-HBP result in correction of RBBB and $L A H B($ narrow $Q R S)$

The other target for physiological pacing is the LBB area pacing (LBBAP) and the recent left septal pacing. Huang et al [20] first reported successful direct LBBAP after a failed HBP in a patient with heart failure and LBBB. It resulted in the correction of LBBB and also improvement in heart failure. LBB is accessed by deep penetration of pacing lead transseptally from the RV side towards the subendocardium of the septal surface of the left ventricle. Since the LBB is compact in proximal $1-2 \mathrm{~cm}$ and then fans out, it gives a larger target area to achieve successful pacing. The optimal site is around $1-1.5 \mathrm{~cm}$ below the His bundle along an imaginary line drawn from distal His signals to RV apex in RAO $30^{\circ}$ [21]. LBBAP usually results in incomplete RBBB pacing, RBBB pattern with relatively longer QRS suggest of left ventricular septal pacing. In LBBP the AV delay has to be programmed $20-30 \mathrm{~ms}$ less than the nominal values as it takes $20-30 \mathrm{~ms}$ for the impulse to reach the ventricular myocardium after LB potential [22]. Concerns regarding the theoretical risk of LV-RV dyssynchrony due to RBBB induced by LBBAP can be sorted by programming the output above the anodal threshold ( the ring of lead lies over the RV septum, result in anodal captures of the right side of the septum) or optimizing the AV delay to allow native fusion (allowing partial conduction through RBB). If his bundle is relatively disease-free RBB can also be captured retrogradely. (Figure 3) 


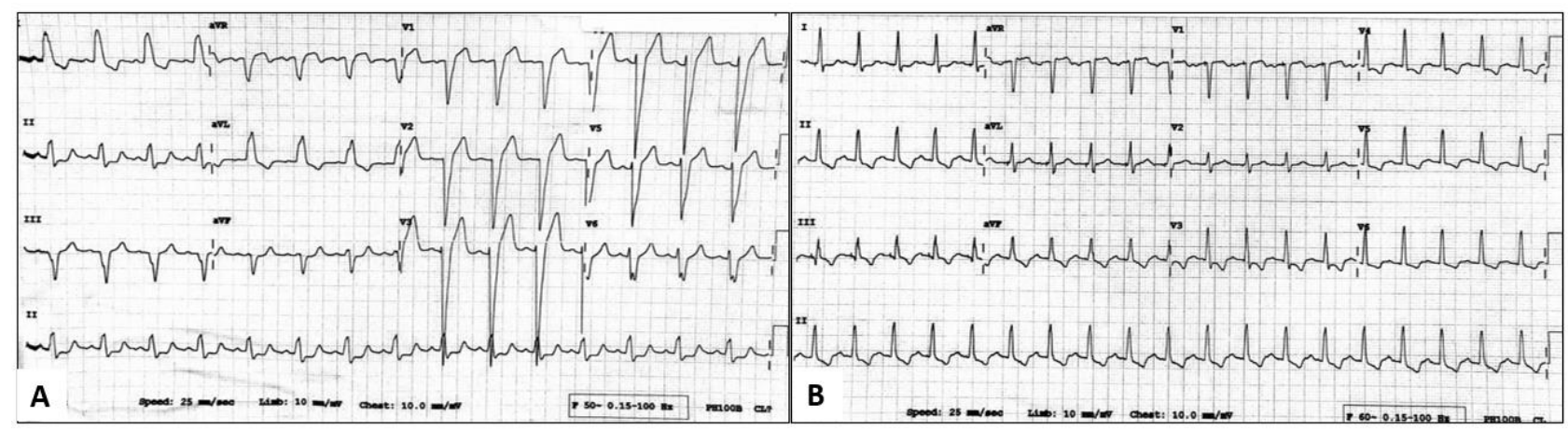

\section{Figure 3. $L B B A P$ in severe $L V$ dysfunction and LBBB A. LBBB (QRSd 160 msec) left axis deviation. B. After LBBAP, QRSd 110 msec, correction of axis. No RBBB, $A V$ delay optimized to promote native conduction via $R B B$}

Recently in a proof of concept study temporary left ventricular septal pacing (LVSP) pacing was shown to provide short-term hemodynamic improvement and electrical resynchronization, which was shown to be as good as during $\mathrm{BiV}$ and possibly comparable to $\mathrm{HB}$ pacing [23]. The concept of LVSP pacing originates from the fact that in a normal heart the LV septal area is the earliest to depolarise by septal fascicles, so LVSP would provide a near-physiological activation. In an earlier study, MafiRad et al. demonstrated the feasibility of transvenous LVSP using a modified version of the Medtronic 3830 lead (Medtronic, Dublin, Ireland), with a long 4-mm screw in patients with sinus node dysfunction [24].Permanent placement of an LVSP lead by transvenous approach through the interventricular septum is feasible in patients. LVSP preserves acute left ventricular pump function. This new pacing method could serve as an alternative and hemodynamically preferable approach for antibradycardia pacing.

\section{Conduction System Pacing for antibradycardia pacing}

An initial feasibility study by Deshmukh et al [25]. paved the way for achieving transvenous permanent HBP in patients. He could achieve successful HBP in 12 of 18 patients with atrial fibrillation undergoing AV node ablation. Similar results were demonstrated in a larger series of patients with acute improvement in hemodynamics, improvement in LVEF, and exercise performance during a mean follow-up of 42 months [26]. Initial studies were done using conventional hardware with a manually shaped stylet to access His bundle area, but with later development of specialized hardware( like 3830 Select Sure Lead \& C315 preshaped catheter, Medtronic Inc., Minneapolis, MN, USA) the technique gained popularity and the learning curve improved resulting in better acute results [27]. Further it was shown by Catanzariti et al [28].that HBP mode compared to RV pacing, resulted in marked improvements in echocardiographic indices of ventricular synchrony, LVEF, and reduction in mitral regurgitation. It was the first demonstrated evidence of physiological superiority of HBP as it does not induce ventricular dyssynchrony like conventional right ventricular apical pacing.

Initial studies did establish $\mathrm{HBP}$ as an alternative strategy for antibradycardia pacing but still, limited data was available regarding its medium to long-term clinical outcomes. Sharma et al [29]. first reported encouraging evidence in favor of HBP over RVP in patients requiring pacemaker implantation. At 2 year follow-up, HBP resulted in significant reduction in $\mathrm{HFH}$ in patients with \% VP > 40\% ( $2 \%$ vs $15 \%$, $\mathrm{P}=0.02)$. The extending follow-up of 5 years in the above cohort, demonstrated a reduction in both HFH and death (32\% vs 53\%; hazard ratio 1.9; $\mathrm{P}=.04)$. As was expected because of the higher pacing threshold needed in HBP at baseline as well as an increase in threshold over time, the need of pulse generator replacement (PGR) was more with HBP compared to RVP ( $9 \%$ vs $1 \%$ ). Also, lead revision was done in $6.7 \%$ cases in the HBP group vs $3 \%$ in the RVP group..$^{30}$ In the largest cohort study to date comparing HBP vs RVP ( $N=765)$ with the mean follow-up duration for the entire cohort being $725 \pm 423$ days. HBP resulted in significant reduction in the primary endpoint of death, $\mathrm{HFH}$, or upgrade to BiVP compared to RVP (25\% vs $32 \%$; hazard ratio [HR]: $0.71 ; 95 \%$ confidence interval $[\mathrm{CI}]: 0.534$ to $0.944 ; \mathrm{p}=0.02)$. This difference was more pronounced in patients with $\% \mathrm{VP}>20 \%$. Also, data showed a trend toward reduced mortality in HBP $(17.2 \%$ vs. $21.4 \%$, respectively; $\mathrm{p}=$ 0.06). In the HBP group, the ventricular lead revision was required in 14 patients $(4.2 \%)$ [31].

HBP on merit looks like an ideal physiological pacing modality and no doubt effectively correct pacing-induced dyssynchrony. But as is evident from the data regarding HBP, it is consistently associated with high pacing threshold compared to RVP. Also in about $10 \%$ of cases, there may be a subacute increase in the pacing threshold. It was not a surprise that the long-term study showed increased PGR in the HBP group than RVP [30].There are technical issues in HBP since the target area is small (His bundle is only $\sim 1-2 \mathrm{~mm}$ in diameter), it can be challenging at times even in expert hands. HBP may be unsuccessful in 10-15\% of patients because of various reasons. There can be programming issues like ventricular undersensing( low $\mathrm{R}$ wave sensed amplitude), far-field atrial over sensing, and at times atrial capture. There are concerns of injury to His bundle and progression of the distal block [32]. And not all LBBB can be corrected by HBP or it may require an unacceptably high pacing threshold.

The above issues can largely be mitigated by LBBAP, which has emerged as an alternative physiological pacing strategy. LBBAP has been shown to have higher rates of implant success, significantly better electrical parameters (pacing threshold and sensed $\mathrm{R}$ wave), and lower lead-related complications [33]. Since the target pacing area is wider (widespread of LB fascicles), LBBAP technically appears to be easier than HBP, and the implant technique is reliable. Another anatomical advantage of LBBAP is that the pacing site can be distal to the pathological or vulnerable region in the conduction system. Prospective studies have demonstrated that permanent LBBP assures a stable threshold, a narrow QRS duration, and preserved left ventricular synchrony, with only a few complications [34, 35]. In a larger series of 100 patients, Vijayaraman et al [36]. Demonstrated that LBBAP was successful in $93 \%$ of the patients and had a low pacing threshold which was stable over 3 months of follow-up. 
Patients included were patients of AV block, SND, AV node ablation, CRT, and attempted HBP failure. Interestingly the authors reported that three patients had acute lead dislodgments within $24 \mathrm{~h}$, three others had ventricular septal lead perforation, whereas one developed pericardial effusion. No transient ischemic attacks or thromboembolism occurred in any of the patients during the follow-up.

\begin{tabular}{|c|c|c|c|c|c|c|c|}
\hline Study & $\begin{array}{l}\text { Design and } \\
\text { number of } \\
\text { patients }\end{array}$ & Indication & $\begin{array}{l}\text { Follow- } \\
\text { up } \\
\text { (mean ) }\end{array}$ & $\begin{array}{l}\text { Success } \\
\text { Rate }\end{array}$ & $\begin{array}{l}\text { Pacing } \\
\text { threshold at } \\
\text { implantation } \\
\text { V/ms }\end{array}$ & $\begin{array}{l}\text { Pacing } \\
\text { threshold at } \\
\text { follow-up } \\
\text { (V/ms }\end{array}$ & Outcome \\
\hline \multicolumn{8}{|l|}{ HBP } \\
\hline Deshmukh et $\mathrm{al}^{25}$ & $\begin{array}{l}\text { Observational } \\
\text { HBP } n=18\end{array}$ & $\begin{array}{l}\text { AV node } \\
\text { ablation }\end{array}$ & $\begin{array}{l}23 \\
\text { month }\end{array}$ & $66 \%$ & $2.4 \pm 1.0 / 0.5$ & - & Feasibility study \\
\hline Zanon et $\mathrm{al}^{27}$ & $\begin{array}{l}\text { Observational } \\
\text { HBP } n=26\end{array}$ & $\begin{array}{l}\text { Standard } \\
\text { pacemaker } \\
(\mathrm{PM}) \\
\text { indication }\end{array}$ & $\begin{array}{l}3 \\
\text { month }\end{array}$ & $92 \%$ & $2.3 \pm 1.0 / 0.5$ & $2.8 \pm 1.4 / 0.5$ & $\begin{array}{l}\text { Feasibility study of new } \\
\text { system consisting of } \\
\text { steerable catheter and } \\
4.1 \mathrm{~F} \text { screw-in lead. }\end{array}$ \\
\hline Catanzariti et $\mathrm{al}^{28}$ & $\begin{array}{l}\text { Observational } \\
\text { HBP n=24 } \\
\text { Additional } \\
\text { RVP- } \\
\text { permanent or } \\
\text { temporary }\end{array}$ & $\begin{array}{l}\text { SSS } \\
\text { AV block }\end{array}$ & $\begin{array}{l}7.5 \\
\text { month }\end{array}$ & $96 \%$ & - & - & $\begin{array}{l}\text { Improved ventricular } \\
\text { synchrony indices. } \\
\text { Reduction in MR, } \\
\text { Improved Tei index } \\
\text { No difference between } \\
\text { S-HBP \& NS-HBP }\end{array}$ \\
\hline $\begin{array}{l}\text { Sharma et al. }{ }^{29} \\
\text { Vijayaraman et } \\
\text { al. }^{30}\end{array}$ & $\begin{array}{l}\begin{array}{l}\text { Prospective } \\
\text { observational }\end{array} \\
\text { HBP n=94 } \\
\text { RVP n=98 }\end{array}$ & $\begin{array}{l}\text { Pacemaker } \\
\text { indication }\end{array}$ & 2 year & $\begin{array}{l}\text { HBP - } \\
80 \%\end{array}$ & $\begin{array}{l}\text { HBP- } 1.35 \pm \\
0.9 / 0.5 \\
\text { RVP- } 0.6 \pm \\
0.5 / 0.5\end{array}$ & - & $\begin{array}{l}\text { Reduction in death or } \\
\text { HFH (if } \% \text { VP }>40 \% \text { ) } \\
32 \% \text { vs } 53 \%, \mathrm{p}=0.04 \\
\text { Lead revision } 6.7 \% \\
\text { vs3\% } \\
\text { PGR } 9 \% \text { vs } 1 \%\end{array}$ \\
\hline $\begin{array}{l}\text { Abdelrahman et } \\
\text { al. } .^{31}\end{array}$ & $\begin{array}{l}\text { Prospective } \\
\text { Case control } \\
\text { HBP } n=332 \\
\text { RVP } n=433\end{array}$ & $\begin{array}{l}\text { pacemaker } \\
\text { indication }\end{array}$ & $\begin{array}{l}24 \\
\text { month }\end{array}$ & $\begin{array}{l}\text { HBP - } \\
92 \%\end{array}$ & $\begin{array}{l}\text { HBP- } 1.30 \pm \\
0.85 / 0.79 \pm \\
0.26 \\
\text { RVP- } \\
0.59 \pm 0.42 / 0.5 \\
\pm 0.03\end{array}$ & $\begin{array}{l}1.56 \pm \\
0.95 / 0.78 \pm \\
0.30 \\
0.76 \pm 0.29 \\
/ 0.46 \pm 0.09\end{array}$ & $\begin{array}{l}\text { Death, HFH, or upgrade } \\
\text { to BiVP was } \\
\text { significantly reduced in } \\
\text { HBP }(25 \% \text { vs } 32 \% \text {, } \\
\text { p=0.02) }\end{array}$ \\
\hline \multicolumn{8}{|l|}{ LBBAP } \\
\hline Chen et al. ${ }^{35}$ & $\begin{array}{l}\text { Prospective } \\
\text { Case control } \\
\text { LBBP } n=20 \\
\text { RVP } n=20\end{array}$ & $\begin{array}{l}\text { pacemaker } \\
\text { indication }\end{array}$ & $\begin{array}{l}3 \\
\text { month }\end{array}$ & $\begin{array}{l}\text { LBBP- } \\
100 \%\end{array}$ & $\begin{array}{l}\text { LBBP-0.73 } \pm \\
0.20 \mathrm{~V} / 0.5 \\
\text { RVP-0.61 } \pm \\
0.23 \mathrm{~V} / 0.5\end{array}$ & & $\begin{array}{l}\text { LBBP has low pacing } \\
\text { threshold , and } \\
\text { significantly narrower } \\
\text { QRS duration in LBBP } \\
\text { than RVAP }(11.85 \pm \\
10.77 \text { ms vs. } 160.15 \pm \\
15.04 \mathrm{~ms}, P<0.001)\end{array}$ \\
\hline
\end{tabular}




\begin{tabular}{|c|c|c|c|c|c|c|c|}
\hline Study & $\begin{array}{l}\text { Design and } \\
\text { number of } \\
\text { patients }\end{array}$ & Indication & $\begin{array}{l}\text { Follow- } \\
\text { up } \\
\text { (mean ) }\end{array}$ & $\begin{array}{l}\text { Success } \\
\text { Rate }\end{array}$ & $\begin{array}{l}\text { Pacing } \\
\text { threshold at } \\
\text { implantation } \\
\text { V/ms }\end{array}$ & $\begin{array}{l}\text { Pacing } \\
\text { threshold at } \\
\text { follow-up } \\
(\mathrm{V} / \mathrm{ms}\end{array}$ & Outcome \\
\hline $\begin{array}{l}\text { Vijayaraman et } \\
\text { al. }{ }^{36}\end{array}$ & $\begin{array}{l}\text { prospective } \\
\text { Observational } \\
\text { LBBAP n= } \\
100\end{array}$ & $\begin{array}{l}\text { AV block } \\
\text { Sinus node } \\
\text { dysfunction } \\
\text { CRT } \\
\text { HBP failure }\end{array}$ & $\begin{array}{l}3 \\
\text { month }\end{array}$ & $93 \%$ & $\begin{array}{l}0.6 \pm 0.4 \mathrm{~V} @ \\
0.5 \mathrm{~ms}\end{array}$ & - & $\begin{array}{l}\text { Feasibility study } \\
\text { Stable pacing threshold }\end{array}$ \\
\hline
\end{tabular}

Table 1: Conduction System Pacing for antibradycardia pacing

\section{Conduction System Pacing for Cardiac resynchronization therapy}

The traditional method to achieve cardiac resynchronization is placing an LV lead in the posterior or postero-lateral vein of the coronary sinus and additional lead in RV (BVP). Randomized studies have already established BVP as an effective therapy in addition to guideline-directed medical therapy for improving morbidity and mortality in heart failure with reduced ejection fraction (HFrEF) [37,38]. The ideal patients for BVP are patients having wide QRS with LBBB. BVP is not without limitations, about $30 \%$ of patients having BVP are either poor responders or nonresponses[37,39]. The procedure itself is technically challenging and is further limited by anatomical factors like lack of suitable venous branches, phrenic nerve stimulation, and high pacing thresholds. And there is a certain subgroup of patients of HFrEF, such as patients with normal QRSd and RBBB, who do not derive benefit [40]. CSP offers an option as a single lead solution instead of two leads for CRT and may offer an alternative in anatomically difficult subsets for BVP-CRT.

HBP can correct bundle branch block ( both $\mathrm{LBBB}$ and $\mathrm{RBBB}$ ) by recruiting $\mathrm{LBB}$ or $\mathrm{RBB}$ fibers distal to the block, effectively narrowing QRSd and will result in correction of electro-mechanical dyssynchrony. The data supporting HBP for CRT are primarily from single or multicentric observational studies. The studies were done in patients with indication for CRT and had reported success rates varying from 56\% (9 in 16 patients ) [41]. in the earliest reported study to $90 \%$ (95 of 106 patients) in a recently reported study ${ }^{42}$. Indicating a role of evolving technique and hardware. These studies have consistently shown a significant narrowing of QRSd and correction of LBBB, improvement in functional class and LV function, and better quality of life. In one of the first multicenter prospective, randomized controlled trials, Upadhyay et al [43]. enrolled a total of 41 patients with severe LV dysfunction with indication for CRT into the His-CRT group $(n=21)$ versus BVP-CRT group $(n=20) .65 \%$ of the patients were having coronary artery disease and mean QRSd $168 \pm 18 \mathrm{~ms}$ [left bundle branch block pattern $=35$, right bundle branch block $=2$, paced $=3$ ]. At a median follow-up of 6.2 months, significant improvements in median LVEF relative to baseline were seen in both His-CRT and BVP-CRT patients. His-CRT was not superior to BiV-CRT with regard to LVEF improvement (median +9.1\% [IQR: $5.0 \%$ to $14.4 \%$ ] vs. +5.2 [IQR: $1.5 \%$ to $11.3 \%$ ]; $\mathrm{p}=0.33$ ) or rate of echocardiographic response $\geq 5 \%(76 \%$ vs. $53 \% ; p=0.13)$. The study was underpowered and was limited by a high crossover rate. Crossover occurred in $48 \%$ of patients in the His-CRT group and $26 \%$ of patients in the BiV-CRT group. The most common reasons for crossover from HisCRT were the inability to correct QRSd(n $=5)$, among them, one-half of patients exhibited nonspecific intraventricular conduction delay (IVCD), which is unlikely to be corrected by His-CRT alone. Most of the data for His-CRT is from short-term to mid-term follow up, recently long-term outcome data was published for patients with HFrEF and LBBB $(n=74)$. In this single-center prospective observational study, HBP was successful in $75.7 \%$ of the patients. There was a significant improvement in LVEF( super-responder) and NYHA class. The HBP threshold for LBBB correction remained stable at 3-year follow-up (with an acute threshold of $2.13 \pm 1.19 \mathrm{~V} / 0.5 \mathrm{~ms}$ and $2.29 \pm 0.92 \mathrm{~V} / 0.5 \mathrm{~ms}$ at follow-up) [44].

IVCD poses a limitation for HBP particularly if there is no His-Purkinje conduction disease (HPCD) and more of myocardial cell-to-cell conduction delay. In such situations, a strategy of HBP in conjunction with sequential LV pacing termed as His -Optimised CRT ( HOT-CRT) may be effective. HOT-CRT was evaluated in a small series of patients with LBBB/IVCD by Vijayaraman et al [45]. in whom HBP alone was not effective $(n=27)$. These patients underwent additional LV epicardial lead implantation, resulting in improved electrical resynchronization when compared with conventional BVP or HBP alone. $84 \%$ were clinical responders while $92 \%$ showed an echocardiographic response. BVP-CRT is not effective in a subgroup of patients of HFrEF with Right Bundle Branch Block (RBBB) if there is no pacing requirement. HBP can correct RBBB and restore RV-LV synchrony. Does HBP will help in patient of $\mathrm{HFrEF}$ and RBBB was evaluated by Sharma et al [46].In this retrospective observational study it was shown that HBP resulted in a significant narrowing of QRS from $158 \pm 24 \mathrm{~ms}$ to $127 \pm 17 \mathrm{~ms}$ ( $\mathrm{p}=0.0001)$, with an improvement in LVEF ( $31 \pm 10 \%$ to $39 \pm 13 \%)$ ( $\mathrm{p}=0.004)$. The overall success rate of $\mathrm{HBP}$ was $95 \%$ (37 of 39 patients) and complete correction of RBBB could be achieved in $78 \%$ of cases. This was the first study indicating that HBP-CRT may be a promising strategy in patients with RBBB and HFrEF.

HBP has its limitations as discussed above and not surprisingly left bundle branch area pacing (LBBAP) is being touted as a promising alternative to BVP-CRT. No doubt LBBAP will be more effective in overcoming LBBB than HBP alone and it has been shown to achieve comparable LV activation times and synchrony parameters [47]. The theoretical LV-RV dyssynchrony resulting from LBBAP can be mitigated to large extent by optimal programming. In the first feasibility study reported by Zhang et al [48]. In 11 patients with CRT indication. LBBAP resulted in significant narrowing in the QRSd as well as improvement in LVEF with a decrease in BNP level in a mean follow-up of 6.7 months. Subsequent case-control studies have consistently shown significant QRS narrowing, and greater LVEF improvement and percentage of echocardiographic response in patients with LBBAP compared with BVP in short and medium-term follow-up [49,50] Huang et al [51]. reported 97\% success with low and stable pacing threshold with LBBAP in medium-term follow-up in nonischemic cardiomyopathy CRT candidates. In addition to improvement in LVEF and functional class, they reported no deaths or heart failure hospitalizations during follow-up. In a recently published multi-centric retrospective, observational study including 325 patients with CRT indication where LBBAP was attempted. LBBAP was successful in $85 \%$ of the patients and the pacing parameters were stable during a mean follow-up of $6 \pm 5$ months. The results were consistent with previously reported smaller studies. The super response was more frequent among nonischemic cardiomyopathy patients than ischemic patients $(41 \%$ vs. $18 \% ; \mathrm{p}<0.01$ ) and numerically more in LBBB than those without LBBB [52]. 
Very recently LVSP has also been proposed as an alternative to BIVCRT, as mentioned above, in a proof of concept study it has shown to preserve mechanical synchrony and improved hemodynamics. Anecdotal case reports have shown favorable results. ${ }^{53}$ Similar to the HOT-CRT strategy, LBBP optimized CRT (LOT-CRT) can be used for patients not deriving optimal QRSd narrowing with LBBAP. Non-responders to BIVCRT are an important group of patients in need of therapeutic remedies. CSP has shown improvements in LVEF and NYHA functional class in small studies of BIV-CRT non-responders[42-54]

\begin{tabular}{|c|c|c|c|c|c|c|}
\hline Study & $\begin{array}{l}\text { Design and number } \\
\text { of patients }\end{array}$ & $\begin{array}{l}\text { Success } \\
\text { rate }\end{array}$ & $\begin{array}{l}\text { Follow - } \\
\text { up (mean) }\end{array}$ & $\begin{array}{l}\text { QRSd (Pre and at } \\
\text { follow-up) ms }\end{array}$ & $\begin{array}{l}\text { LVEF ( Pre and } \\
\text { at follow-up )\% }\end{array}$ & Outcome \\
\hline \multicolumn{7}{|l|}{ HBP-CRT } \\
\hline $\begin{array}{l}\text { Barba-Pichardo } \\
\text { et al. }{ }^{41}\end{array}$ & $\begin{array}{l}\text { Observational } \\
\text { HBP-CRT } n=16\end{array}$ & $56 \%$ & 31 months & $\begin{array}{l}166 \pm 8 \text { to } \\
97 \pm 9\end{array}$ & $\begin{array}{l}29 \pm 0.05 \text { to } \\
36 \pm 0.05\end{array}$ & $\begin{array}{l}\text { Improved LVEF } \\
\text { Improved NYHA } \\
\text { class }\end{array}$ \\
\hline Sharma et al. ${ }^{42}$ & $\begin{array}{l}\text { Observational } \\
\text { HBP-CRT } n=106\end{array}$ & $90 \%$ & 14 months & $157 \pm 33$ to $117 \pm 18$ & $\begin{array}{l}30 \pm 10 \text { to } 43 \pm \\
13\end{array}$ & $\begin{array}{l}\text { Feasibility study } \\
\text { Improved LVEF } \\
\text { Improved NYHA } \\
\text { class }\end{array}$ \\
\hline $\begin{array}{l}\text { Upadhyay et } \\
\text { al. } 43\end{array}$ & $\begin{array}{l}\text { Prospective, } \\
\text { randomized } \\
\text { controlled trial } \\
\text { HBP-CRT n }=21 \\
\text { BVP-CRT n }=20\end{array}$ & $\begin{array}{l}\text { HBP-52\% } \\
\text { BVP-74\% }\end{array}$ & $\begin{array}{l}6.2 \text { month } \\
\text { (median) }\end{array}$ & $\begin{array}{l}\text { HBP- } 172 \pm 16 \text { to } 144 \\
\pm 30 \\
\text { BVP }-165 \pm 18 \text { to } 152 \\
\pm 30\end{array}$ & $\begin{array}{l}\text { HBP-26.3 to } \\
31.9 \\
\text { BVP-30.5 to } \\
34.0\end{array}$ & $\begin{array}{l}\text {-No difference in } \\
\text { electrocardiograph } \\
\text { ic or } \\
\text { echocardiograhic } \\
\text { parameters }\end{array}$ \\
\hline Huang et al. ${ }^{44}$ & $\begin{array}{l}\text { Observational study } \\
\text { HBP-CRT } n=74\end{array}$ & $75.7 \%$ & 3 year & 171 to 113 & $\begin{array}{l}32.4 \pm 8.9 \text { to } \\
55.9 \pm 10.7\end{array}$ & $\begin{array}{l}\text {-LBBB correction } \\
\text { threshold } \\
\text { remained stable } \\
\text {-Improved LVEF } \\
\text {-Improved NYHA } \\
\text { class }\end{array}$ \\
\hline \multicolumn{7}{|l|}{ LBBAP-CRT } \\
\hline Zhang et al. ${ }^{48}$ & $\begin{array}{l}\text { Observational, } \\
\text { LBBAP-CRT } n=11\end{array}$ & $100 \%$ & 6.7 & $\begin{array}{l}180.00 \pm 15.86 \text { to } \\
129.09 \pm 15.94\end{array}$ & $\begin{array}{l}32 \% \pm 5.0 \%, \text { to } \\
5->20 \% \\
\text { improvement }\end{array}$ & $\begin{array}{l}\text {-Improved LVEF } \\
\text {-Improved NYHA } \\
\text { class } \\
\text {-Decreased BNP }\end{array}$ \\
\hline Wang et al. ${ }^{49}$ & $\begin{array}{l}\text { Case control } \\
\text { LBBAP-CRT } n=10 \\
\text { BVP-CRT } n=30\end{array}$ & $100 \%$ & 6 & $\begin{array}{l}\text { LBBP- } 184 \pm 19 \\
\text { to } 123 \pm 17 \\
\text { BVP- } 175 \pm 19 \\
\text { to } 142 \pm 15\end{array}$ & $\begin{array}{l}\text { LBBP- } 27 \pm 4 \text { to } \\
46 \pm 9 \\
\text { BVP- } 26 \pm 5 \text { to } \\
39 \pm 12\end{array}$ & $\begin{array}{l}\text {-Greater Improved } \\
\text { in NYHA class, } \\
\text { QRS narrowing } \\
\text { and response rate }\end{array}$ \\
\hline Li et al. ${ }^{50}$ & $\begin{array}{l}\text { Case control } \\
\text { LBBAP-CRT } n=37 \\
\text { BIV-CRT } n=54\end{array}$ & $100 \%$ & 6 & $\begin{array}{l}\text { LBBP- } 176 \pm 17 \text { to } \\
125 \pm 12 \\
\text { BIV- } \quad \text { to } 155 \pm 22\end{array}$ & $\begin{array}{l}\text { LBBP- } 29 \pm 5 \text { to } \\
44 \pm 9 \\
\text { BIV - }- \text { to } \\
35 \pm 11\end{array}$ & $\begin{array}{l}\text { greater reduction } \\
\text { in the QRSd, } \\
\text { greater increase in } \\
\text { LVEF and more } \\
\text { super response }\end{array}$ \\
\hline Huang et al. ${ }^{51}$ & LBBAP-CRT $n=63$ & $97 \%$ & 18 & $169 \pm 16$ to $118 \pm 12$ & $33 \pm 8$ to $55 \pm 10$ & $\begin{array}{l}\text { Improved LVEF } \\
\text { Improved NYHA } \\
\text { class }\end{array}$ \\
\hline $\begin{array}{l}\text { Vijayaraman et } \\
\text { al. }{ }^{52}\end{array}$ & $\begin{array}{l}\text { Observational } \\
\text { LBBAP-CRT } n=325\end{array}$ & $85 \%$ & 6 & $152 \pm 32$ to $137 \pm 22$ & $33 \pm 10$ to $44 \pm 11$ & $\begin{array}{l}\text { Improved LVEF } \\
\text { Improved NYHA } \\
\text { class }\end{array}$ \\
\hline
\end{tabular}




\section{Current status and limitations of Conduction System Pacing}

As per the recent $2018 \mathrm{ACC} / \mathrm{AHA} / \mathrm{HRS}$ guideline, HBP has been given a class IIa indication in patients with pacemaker requirements with LVEF $<50 \%$ and \%VP $>40 \% .^{6}$ For patients with normal LVEF irrespective of pacing requirement, still there are no guideline-directed indications for CSP. Regarding LBBAP still it does not find an indication in the guidelines. The accumulating experience and the available data though mostly from non-randomized studies make a case for both HBP and LBBAP. It is expected that future guidelines updates may incorporate more indications for CSP. CSP for CRT looks most promising as per the evidence, it gives a single lead solution for achieving cardiac synchronization in most of the eligible CRT patients. Comparison of HBP and LBBAP puts LBBAP at an advantageous status as per the short and medium-term follow-up data. (Table 3) The most significant limitation with HBP is the inability to achieve a low pacing threshold and sub-acute increase in threshold resulting in more PGR in long-term follow-up. In a multicentric study on HBP for CRT significant increase in HBP threshold ( $>2 \mathrm{~V}$ increase in capture threshold from implant or capture threshold $>5$ $\mathrm{V}$ at $1 \mathrm{~ms}$ ) was observed in $7.4 \%$ cases with loss of BBB recruitment in some [42]. The reasons for the sub-acute increase in threshold may be because of disease progression, microdislodgement, or hardware associated issues, but it remains speculative. Regarding LBBAP, as discussed the pacing thresholds are found to be stable but we still do not have long-term safety data, as it has been widely used only since $2017 .{ }^{55}$ LV septal perforation can happen during the implantation or maybe later. Even the lead may perforate and migrate into LV. ${ }^{56}$ Acute Lead dislodgement with loss of capture has been reported in Vijayaraman et al. ${ }^{36}$ in 3 out of 93 patients who underwent LBBP also 1 case of pericardial effusion has been reported by them. Additionally, there is a theoretical risk of injury to RBB, septal artery perforation, and thromboembolism from exposed LV subendocardial lead. Also, it remains to be answered how the intramyocardial portion of lead will behave in the long-term ( any risk of lead fracture or fatigue due to repeated contraction) or if required how safe lead extraction would be.

\section{Future directions and conclusions}

For patients with LV dysfunction requiring pacemaker implantation and those who are candidates for CRT, CSP has the potential to become alternative therapy of choice.

Antibradycardia therapy with HBP seems limited by its high threshold of pacing particularly in relatively younger patients, as they may require repeated PGR. LBBAP including LVSP looks promising in patients requiring pacing because of bradycardia. Work is needed to develop dedicated sensing algorithms to reduce far-field atrial sensing and to bring modified His specific pacing systems to improve pacing thresholds and stability. Similarly, specific modifications are needed for LBBAP particularly in terms of hardware. The systems presently used for HBP or LBBP were initially designed for RV pacing ( the lead and catheter ). So dedicated system is the need of the hour and thankfully some new dedicated systems are already available in some parts. Additionally, despite the current evidence, we need further long-term data in form of prospective randomized clinical trials to establish the definite role of each of the CSP modalities. HBP or LBBAP or LVSP, when and where?

\begin{tabular}{|c|c|c|}
\hline & $\begin{array}{l}\text { His bundle pacing } \\
\text { (HBP) }\end{array}$ & Left bundle pacing area pacing (LBBAP) \\
\hline Target pacing segment & Small target area & Larger target area \\
\hline Technical aspect & Challenging & Simpler \\
\hline Pacing threshold & High pacing threshold & Similar as in RVP \\
\hline R-wave sensing & Low R-wave amplitude & Good R-wave amplitude \\
\hline Success rate & Relatively lower success rate & Higher success rate \\
\hline LBBB correction & $\begin{array}{l}\text { LBBB may not be corrected in } 10-30 \% \text { of } \\
\text { patients }^{17}\end{array}$ & More effective in correcting LBBB \\
\hline Pacing threshold on follow-up & $10 \%$ cases may have increase & Stable pacing threshold \\
\hline PG battery depletion & Early need of PGR & Same as with RVP \\
\hline Complications & $\begin{array}{l}\text { Battery depletion, } \\
\text { Lead revision due to HBP failure, Lead } \\
\text { dislodgment, } \\
\text { Ventricular under sensing, } \\
\text { Far -field atrial oversensing, } \\
\text { Atrial capture, } \\
\text { His bundle injury }\end{array}$ & $\begin{array}{l}\text { Septal perforation, } \\
\text { Lead dislodgement, } \\
\text { Lead migration into LV, } \\
\text { RBB injury, } \\
\text { Septal artery injury and MI } \\
\text { Thromboembolism }\end{array}$ \\
\hline
\end{tabular}

Table 3: Comparison of HBP and LBBAP 


\section{Reference}

1. Andersen HR, Nielsen JC, Thomsen PE, Thuesen L, Mortensen PT, Vesterlund T, Pedersen AK (1997). Long-term follow-up of patients from a randomised trial of atrial versus ventricular pacing for sick-sinus syndrome. Lancet. Oct 25;35(9086):1210-6. doi: 10.1016/S0140-6736(97)03425-9.

2. Sweeney M, Hellkamp A, Greenspon A et al (2002). Baseline QRS duration $\geq 120$ milliseconds and cumulative percent time ventricular paced predicts increased risk of heart failure, stroke, and death in DDDR-paced patients with sick sinus syndrome in MOST . Pacing Clin Electrophysiol.;25:690.

3. (2002) The DAVID Trial Investigators*. Dual-Chamber Pacing or Ventricular Backup Pacing in Patients With an Implantable Defibrillator: The Dual Chamber and VVI Implantable Defibrillator (DAVID) Trial. JAMA.;288(24):3115-3123.

4. Mark CS Hall (2006) Johan EP Waktare.Developments in Conventional Pacing - Harmful Effects of Pacing the Right Ventricular Apex and Strategies to Avoid it.European Cardiovascular Disease.2(2):1-6

5. Sgarbossa E, Maloney JD, (1992). Pacing and atrioventricular block .Curr Opin Cardiol 7(1): pp. 15-22.

6. Kusumoto FM, Schoenfeld MH, Barrett CN, Edgerton JR, Ellenbogen KA, Gold MR, Goldschlager NF,et al (2018). ACC/AHA/HRS guideline on the evaluation and management of patients with bradycardia and cardiac conduction delay: a report of the American College of Cardiology/American Heart Association Task Force on Clinical Practice Guidelines and the Heart Rhythm Society. J Am Coll Cardiol 2019;74:e51-156.

7. Kawashima T, Sato F (2014). Visualising anatomical evidences on atrioventricular conduction system for TAVI. Int $J$ Cardiol.174:1-6.

8. Anderson RH, Yanni J, Boyett MR, Chandler NJ, Dobrzynski H (2009). The anatomy of the cardiac con- duction system. Clinical Anatomy. 22: 99-113.

9. El-Sherif N, Amay-Y-Leon F, Schonfield C, Scherlag BJ, Rosen K, Lazzara R, et al (1978). Normalization of bundle branch block patterns by distal His bundle pacing. Clinical and experimental evidence of longitudinal dissociation in the pathologic his bundle. Circulation.; 57:473-483.

10. Kaufmann R, Rothberger CJ (1919). Beiträge zur Entstehungsweise extrasystolischer allorhythmien.Zeitschrift für die Gesamte Experimentelle Medizin. 9:104-122.

11. Narula OS (1977). Longitudinal dissociation in the His bundle. Bundle branch block due to asynchronous conduction within the His bundle in man. Circulation.;56(6):996-1006.

12. James TN, Sherf L (1971). Fine structure of the His bundle. Circulation;44:9-28.

13. Teng AE, Lustgarten DL, Vijayaraman P, Tung R, Shivkumar K, Wagner GS, Ajijola OA (2016). Usefulness of His Bundle Pacing to Achieve Electrical Resynchronization in Patients With Complete Left Bundle Branch Block and the Relation Between Native QRS Axis, Duration, and Normalization. Am J Cardiol. Aug 15;118(4):527-34.

14. Teng AE, Massoud L, Ajijola OA (2016). Physiological mechanisms of QRS narrowing in bundle branch block patients undergoing permanent His bundle pacing. J Electrocardiol. 2016;49(5):644-648. doi:10.1016/j.jelectrocard.07.013.

15. Cheng Y, Mowrey K a, Van Wagoner DR, Tchou PJ, Efimov IR (1999). Virtual electrode-induced reexcitation: A mechanism of defibrillation. Circ Res.;85(11):1056-1066.

16. Dandamudi G, Vijayaraman P (2016). How To Perform Permanent His Bundle Pacing In Routine Clinical Practice. Heart Rhythm.;13(6):1362-1366.
17. Vijayaraman P, Chung MK, Dandamudi G, Upadhyay GA, Krishnan K, Crossley G, Bova Campbell K, Lee BK, Refaat MM, Saksena S, Fisher JD, Lakkireddy D; ACC's Electrophysiology Council. His Bundle Pacing. J Am Coll Cardiol. 2018 Aug 21;72(8):927-947.

18. Kawashima, T., Sasaki, H (2005). A macroscopic anatomical investigation of atrioventricular bundle locational variation relative to the membranous part of the ventricular septum in elderly human hearts. Surg Radiol Anat 27, 206-213).

19. Zhang J, Guo J, Hou X, et al (2018). Comparison of the effects of selective and non-selective His bundle pacing on cardiac electrical and mechanical syn- chrony. Europace;20:1010-7.

20. Huang W, Su L, Wu S, et al (2017). A novel pacing strategy with low and stable output: Pacing the left bundle branch immediately beyond the con- duction block. Can J Cardiol;33:1736. e1-3.

21. Huang W, Chen X, Su L, Wu S, Xia X, Vijayaraman P (2019). A beginner's guide to permanent left bundle branch pacing. Heart Rhythm. Dec;16(12):1791-1796.

22. Ponnusamy SS, Arora V, Namboodiri N, Kumar V, Kapoor A, Vijayaraman P (2020). Left bundle branch pacing: A comprehensive review. $J$ Cardiovasc Electrophysiol. Sep;31(9):2462-2473.

23. Salden FCWM, Luermans JGLM, Westra SW, Weijs B, Engels EB, Heckman LIB, Lamerichs $\operatorname{LJM}(2020)$. Short-Term Hemodynamic and Electrophysiological Effects of Cardiac Resynchronization by Left Ventricular Septal Pacing. $J$ Am Coll Cardiol. Feb 4;75(4):347-359.

24. Mafi-Rad M, Luermans JG, Blaauw Y, Janssen M, Crijns HJ, Prinzen FW, Vernooy K (2016). Feasibility and Acute Hemodynamic Effect of Left Ventricular Septal Pacing by Transvenous Approach Through the Interventricular Septum. Circ Arrhythm Electrophysiol. Mar;9(3):e003344.

25. Deshmukh P, Casavant DA, Romanyshyn M, Anderson K (2000). Permanent, direct His-bundle pacing. Circulation. 101:869-877.

26. Deshmukh PM, Romanyshyn M (2004). Direct His-bundle pacing. Pacing Clin Electrophysiol.; 27:862-870.

27. Zanon F, Baracca E, Aggio S, Pastore G, Boaretto G, Cardano P,et al(2006). A feasible approach for direct his-bundle pacing using a new steerable catheter to facilitate precise lead placement. $J$ Cardiovasc Electrophysiol. Jan;17(1):29-33.

28. Catanzariti D, Maines M, Cemin C, Broso G, Marotta T, Vergara G (2006). Permanent direct His bundle pacing does not induce ventricular dyssynchrony unlike conventional right ventricular apical pacing. J Interv Card Electrophysiol.16:81-92.

29. Sharma PS, Dandamudi G, Naperkowski A, Oren JW, Storm RH, Ellenbogen KA, Vijayaraman P (2015). Permanent His-bundle pacing is feasible, safe, and superior to right ventricular pacing in routine clinical practice. Heart Rhythm.12:305-312.

30. Vijayaraman P, Naperkowski A, Subzposh FA, Abdelrahman M, Sharma PS, Oren JW, Dandamudi G, Ellenbogen KA (2018). Permanent His-bundle pacing: long-term lead performance and clinical outcomes. Heart Rhythm. 15:696-702.

31. Abdelrahman M, Subzposh FA, Beer D, Durr B, Naperkowski A, Sun H,et al (2018). Clinical Outcomes of His Bundle Pacing Compared to Right Ventricular Pacing. J Am Coll Cardiol. May 22; 71(20):2319-2330.

32. Vijayaraman P, Dandamudi G (2016). How to Perform Permanent His Bundle Pacing: Tips and Tricks. Pacing Clin Electrophysiol. Dec;39(12):1298-1304.

33. Padala SK, Ellenbogen KA (2020). Left bundle branch pacing is the best approach to physiological pacing. Heart Rhythm O21:5967.

34. Huang W, Su L, Wu S, Xu L, Xiao F, Zhou X, Ellenbogen KA (2017). A Novel Pacing Strategy With Low and Stable Output: 
Pacing the Left Bundle Branch Immediately Beyond the Conduction Block. Can J Cardiol. Dec;33(12):1736.e1-1736.e3.

35. Chen K, Li Y, Dai Y, Sun Q, Luo B, Li C, Zhang S (2019). Comparison of electrocardiogram characteristics and pacing parameters between left bundle branch pacing and right ventricular pacing in patients receiving pacemaker therapy. Europace. Apr 1;21(4):673-680.

36. Vijayaraman P, Subzposh FA, Naperkowski A, Panikkath R, John K, Mascarenhas V, Bauch TD, Huang W (.2019). Prospective evaluation of feasibility and electrophysiologic and echocardiographic characteristics of left bundle branch area pacing. Heart Rhythm.Dec;16(12):1774-1782.

37. Cleland JG, Daubert JC, Erdmann E, et al (2005). The effect of cardiac resynchronization on morbidity and mortality in heart failure. N Engl J Med;352:1539-49.

38. Bristow M.R., Saxon L.A., Boehmer J (2004). Cardiacresynchronization therapy with or without an implantable defibrillator in advanced chronic heart failure. $N$ Engl $J$ Med;350:2140-2150.

39. Singh JP, Klein HU, Huang DT, et al (2011). Left ventricular lead position and clinical outcome in the multicenter automatic defibrillator implantation trial-cardiac resynchronization therapy (MADIT-CRT) trial. Circulation.123:1159-66.

40. Moss AJ, Hall WJ, Cannom DS, et al (2009). Cardiacresynchronization therapy for the prevention of heart-failure events. N Engl J Med;361:1329-38.

41. Barba-Pichardo R, Manovel Sanchez A, Fernandez-Gomez JM, et al (2013). Ventricular resynchronization therapy by direct Hisbundle pacing using an internal cardioverter defibrillator. Europace 15:83-8.

42. Sharma PS, Dandamudi G, Herweg B, Wilson D, Singh R, Naperkowski A, Koneru JN,ET AL(2018). Permanent His-bundle pacing as an alternative to biventricular pacing for cardiac resynchronization therapy: A multicenter experience. Heart Rhythm. Mar;15(3):413-420.

43. Upadhyay GA, Vijayaraman P, Nayak HM, Verma N, Dandamudi G, Sharma PS, Saleem M, Mandrola J, Genovese D, Tung R; HisSYNC Investigators. His Corrective Pacing or Biventricular Pacing for Cardiac Resynchronization in Heart Failure. J Am Coll Cardiol. Jul 9;74(1):157-159.

44. Huang W, Su L, Wu S, et al (2019). Long-term outcomes of His bundle pacing in patients with heart failure with left bundle branch block. Heart;105:137-43.

45. Vijayaraman P, Herweg B, Ellenbogen KA, et al (2019). Hisoptimized cardiac resynchronization therapy to maximize electrical resynchronization. Circ Arrhythm Electrophysiol;12:e006934.

46. Sharma PS, Naperkowski A, Bauch TD, et al(2018). Permanent His bundle pacing for cardiac resynchronization therapy in patients with heart failure and right bundle branch block. Circ Arrhythm Electrophysiol;11:e06613.

47. Strocchi M, Lee AWC, Neic A, et al (2020). His-bundle and left bundle pacing with optimized atrioventricular delay achieve superior electrical synchrony over endocardial and epicardial pacing in left bundle branch block patients. Heart Rhythm 17:1922-9.

48. Zhang W, Huang J, Qi Y, Wang F, Guo L, Shi X, Wu W, Zhou X, Li R (2019). Cardiac resynchronization therapy by left bundle branch area pacing in patients with heart failure and left bundle branch block. Heart Rhythm. Dec;16(12):1783-1790.

49. Wang Y, Gu K, Qian Z, et al (2020). The efficacy of left bundle branch area pacing compared with biventricular pacing in patients with heart failure: A matched case-control study. J Cardiovasc Electrophysiol;31:2068-77.

50. Li X, Qiu C, Xie R, et al (2020). Left bundle branch area pacing delivery of cardiac resynchronization therapy and comparison with biventricular pacing. ESC Heart Fail;7:1711-22.

51. Huang W, Wu S, Vijayaraman P, Su L, Chen X, Cai B, Zou J,et al(2020). Cardiac Resynchronization Therapy in Patients With Nonischemic Cardiomyopathy Using Left Bundle Branch Pacing. JACC Clin Electrophysiol. Jul;6(7):849-858.

52. Vijayaraman P, Ponnusamy S, Cano Ó, Sharma PS, Naperkowski A, Subsposh FA, Moskal P,et al(2021). Left Bundle Branch Area Pacing for Cardiac Resynchronization Therapy: Results From the International LBBAP Collaborative Study Group. JACC Clin Electrophysiol. Feb;7(2):135-147.

53. Gu M, Li H, Hu YR, Niu HX, Hua W (2019). Cardiac resynchronization therapy using left ventricular septal pacing: An alternative to biventricular pacing? HeartRhythm Case Rep. Apr 4;5(8):426-429.

54. Shan P, Su L, Zhou X, et al (2018). Beneficial effects of upgrading to His bundle pacing in chronically paced patients with left ventricular ejection fraction <50. Heart Rhythm;15:405-12.

55. Zhang S, Zhou X, Gold MR(2019). Left Bundle Branch Pacing: JACC Review Topic of the Week. J Am Coll Cardiol. Dec 17;74(24):3039-3049.

56. Ravi V, Larsen T, Ooms S, Trohman R, Sharma PS (2020). Lateonset in- terventricular septal perforation from left bundle branch pacing. HeartRhythm Case Rep.:1-5.
This work is licensed under Creative Commons Attribution 4.0 License

To Submit Your Article Click Here:

Submit Manuscript

DOI: $10.31579 / 2692-9759 / 030$
Ready to submit your research? Choose Auctores and benefit from:

$>$ fast, convenient online submission

$>$ rigorous peer review by experienced research in your field

$>$ rapid publication on acceptance

$>$ authors retain copyrights

$>$ unique DOI for all articles

$>$ immediate, unrestricted online access

At Auctores, research is always in progress.

Learn more https://auctoresonline.org/journals/cardiology-research-andreports- 